\title{
Sequential organ failure assessment score predicts mortality after coronary artery bypass grafting
}

\author{
Chih-Hsiang Chang ${ }^{1,5+}$, Shao-Wei Chen ${ }^{2,5+}$, Pei-Chun Fan ${ }^{1,5}$, Cheng-Chia Lee ${ }^{1,5}$, Huang-Yu Yang ${ }^{1,5}$, Su-Wei Chang ${ }^{4}$,
} Heng-Chih Pan ${ }^{3,5}$, Feng-Chun Tsai ${ }^{2,5}$, Chih-Wei Yang ${ }^{1,5}$ and Yung-Chang Chen ${ }^{1,5^{*}}$ (1)

\begin{abstract}
Background: Mortality after coronary artery bypass grafting (CABG) is generally associated with underlying disease and surgical factors overlooked in preoperative prognostic models. Sequential Organ Failure Assessment (SOFA) and Acute Physiology and Chronic Health Evaluation (APACHE II) scores are widely used in intensive care units for outcome prediction. This study investigated the accuracy of these models in predicting mortality.

Methods: Between January 2010 and April 2013, 483 patients who underwent isolated CABG were enrolled. The clinical characteristics, outcomes, and prognostic model scores of the patients were collected. Discrimination was assessed using the area under the curve approach.
\end{abstract}

Results: Both SOFA and APACHE II scores were effective for predicting in-hospital mortality. Among the organ systems examined in the SOFA, the cardiac and renal systems were the strongest predictors of CABG mortality. Multivariate analysis identified only the SOFA score as being an independent risk factor for mortality.

Conclusion: In summary, the SOFA score can be used to accurately identify mortality after isolated CABG.

Keywords: Coronary artery by pass grafting, Sequential organ failure assessment, Society of thoracic surgeons mortality risk, Mortality, Cardiorenal syndrome

\section{Background}

Studies have reported that the mortality of cardiac surgery ranges from 2.94 to 32.5 according to different surgeries and population [1-3]. Prognostic models developed by the Society of Thoracic Surgeons European System for Cardiac Operative Risk Evaluation for mortality and morbidity are widely used before operations. However, unexpected intraoperative factors might influence the outcomes of these patients. General severity scoring systems, such as the Acute Physiology and Chronic Health Evaluation (APACHE II) [4] and Sequential Organ Failure Assessment (SOFA) [5], are generally used in intensive care units (ICUs) to predict mortality, but their validity in isolated coronary

\footnotetext{
* Correspondence: cyc2356@cgmh.org.tw

${ }^{\dagger}$ Equal contributors

'Kidney Research Center, Department of Nephrology, Chang Gung Memorial Hospital, Linkou Medical Center, Taoyuan, Taiwan

${ }^{5}$ School of medicine, College of Medicine, Chang Gung University, 199 Tung

Hwa North Road, Taoyuan, Taipei 105, Taiwan

Full list of author information is available at the end of the article
}

artery bypass grafting (CABG) patients is not well established [6], Therefore, we undertook a post hoc analysis of a prospectively accumulated database to evaluate the accuracy of the SOFA and APACHE II for predicting postoperative mortality on the date of surgical ICU admission.

\section{Methods}

Study participants and data collection

This clinical study was conducted in full compliance with the ethical principles of the Declaration of Helsinki and was consistent with Good Clinical Practice guidelines and the applicable local regulatory requirements. The local institutional review board of Chang Gung Memorial Hospital approved our study protocol. The requirement for obtaining patient consent was waived because the study utilized prospectively collected data for post hoc analysis. This database was constructed for medical quality assurance. Patients of ages older than 20 years were enrolled in this study. Between January 2010 and April 2013, 
483 consecutive patients who received isolated CABG in a single tertiary referral hospital were investigated. Pertinent data on patients' medical history including clinical characteristics, demographic data, and a scoring system were extracted from this database. Congestive heart failure (CHF, based on Framingham criteria and defined using New York Heart Association classifications), shock (defined as hypotension with systolic arterial blood pressure of $90 \mathrm{mmHg}$ despite adequate fluid resuscitation), and myocardial infarction (MI; defined according to the 2007 Expert Consensus Document of Circulation from the European Heart Journal) were evaluated. Illness severity was assessed using APACHE II and SOFA [4, 5] scores determined on the day of ICU admission. The primary outcome was in-hospital mortality. Patients who underwent CABG received standard medical care according to the 2011 American College of Cardiology Foundation/ American Heart Association guidelines for CABG [7].

\section{Statistical analysis}

The Kolmogorov-Smirnov test was used to determine the normal distribution for each variable. Student's $t$ test was used to compare the means of continuous variables and normally distributed data; otherwise, the MannWhitney $U$ test was used. Categorical data were tested using the chi-square test or Fisher exact test. Furthermore, the Hosmer-Lemeshow goodness-of-fit test was used for calibration when evaluating the number of observed and predicted deaths for the entire range of death probabilities. Discrimination was assessed using the area under the curve (AUC), which was compared using a nonparametric approach [8]. Cumulative survival curves as a function of time were generated using the KaplanMeier approach and compared using a log-rank test. All statistical tests were 2 -tailed; a value of $P<.05$ was considered statistically significant.

\section{Results}

\section{Study population characteristics}

The 483 patients were all adults and had a mean age of 62.9 years; of them, $17.6 \%(n=85)$ were female. Overall in-hospital mortality was $9.9 \%$. All patient characteristics are listed in Table 1. Compared with the survival group, the mortality group was older, was more likely to have end-stage renal disease (ESRD), and was more likely to be on ventilator support before surgery. Those who died also had higher creatinine $(\mathrm{Cr})$, lower albumin (ALB), and lower hemoglobin $(\mathrm{Hb})$ levels and poorer preoperative heart conditions such as greater more preoperative intra-aortic balloon pumping (IABP) usage, extracorporeal membrane oxygenation (ECMO) usage, more shock, more recent $\mathrm{MI}$, and a lower ejection fraction. Table 2 lists the surgical details and postoperative data of the patients. The nonsurvivors required the surgery more
Table 1 Preoperative demographic data and clinical characteristics of survival and mortality groups (Expressed as Mean \pm Standard Error)

\begin{tabular}{|c|c|c|c|c|}
\hline & $\begin{array}{l}\text { All Patients } \\
(n=483)\end{array}$ & $\begin{array}{l}\text { Survival } \\
(n=435)\end{array}$ & $\begin{array}{l}\text { Mortality } \\
(n=48)\end{array}$ & $p$-value \\
\hline \multicolumn{5}{|c|}{ Preoperative demographic data } \\
\hline Age (years) & $62.9 \pm 0.5$ & $62.3 \pm 0.5$ & $68.8 \pm 1.5$ & $<0.001$ \\
\hline Sex, female (\%) & $85(17.6)$ & $75(17.2)$ & $10(20.8)$ & 0.535 \\
\hline Diabetes mellitus (\%) & $252(52.2)$ & $223(51.3)$ & $29(60.4)$ & 0.228 \\
\hline Hypertension (\%) & $376(77.8)$ & $340(78.2)$ & $36(75.0)$ & 0.617 \\
\hline ESRD (\%) & $57(11.8)$ & $43(9.9)$ & $14(29.2)$ & $<0.001$ \\
\hline Shock (\%) & $66(13.7)$ & $42(9.7)$ & $24(50.0)$ & $<0.001$ \\
\hline $\begin{array}{l}\text { Mechanical ventilation, } \\
\text { n (\%) }\end{array}$ & $45(9.3)$ & $33(7.6)$ & $12(25.0)$ & $<0.001$ \\
\hline $\begin{array}{l}\text { Serum Creatinine } \\
(\mathrm{mg} / \mathrm{dL})\end{array}$ & $2.0 \pm 0.12$ & $1.79 \pm 0.11$ & $3.85 \pm 0.51$ & $<0.001$ \\
\hline Albumin (g/L) & $3.85 \pm 0.03$ & $3.89 \pm 0.30$ & $3.25 \pm 0.93$ & $<0.001$ \\
\hline Hemoglobin (g/dL) & $12.5 \pm 0.1$ & $12.7 \pm 0.1$ & $10.8 \pm 0.3$ & $<0.001$ \\
\hline hs-CRP (mg/L) & $26.4 \pm 2.7$ & $23.1 \pm 2.7$ & $58.6 \pm 16.3$ & $<0.001$ \\
\hline \multicolumn{5}{|l|}{ Preoperative heart condition } \\
\hline CHF FC III/IV (\%) & $77(15.9)$ & $63(14.5)$ & $14(29.2)$ & 0.008 \\
\hline IABP, (\%) & $60(12.4)$ & $40(9.2)$ & $20(41.7)$ & $<0.001$ \\
\hline ECMO, (\%) & $11(2.3)$ & $7(1.6)$ & $4(8.3)$ & 0.017 \\
\hline Ejection fraction (\%) & $53 \pm 1$ & $54 \pm 1$ & $40 \pm 2$ & $<0.001$ \\
\hline Recent MI, (\%) & $225(46.6)$ & $191(43.9)$ & $34(70.8)$ & 0.001 \\
\hline CAD vessels & $2.80 \pm 0.02$ & $2.8 \pm 0.02$ & $2.8 \pm 0.07$ & 0.437 \\
\hline \multicolumn{5}{|l|}{ Preoperative scores } \\
\hline STS-risk of mortality & $7.7 \pm 0.6$ & $5.4 \pm 0.5$ & $27.9 \pm 3.1$ & $<0.001$ \\
\hline EuroSCORE II & $6.8 \pm 0.4$ & $5.4 \pm 0.4$ & $18.9 \pm 2.1$ & $<0.001$ \\
\hline
\end{tabular}

Abbreviations: CAD coronary artery disease, CHF FC congestive heart failure functional class, ECMO Extracorporeal Membrane Oxygenation, ESRS End stage renal disease, EuroSCORE European System for Cardiac Operative Risk Evaluation, hs-CRP high-sensitivity C-reactive protein, IABP intra-aortic balloon pump, ICU intensive care unit, MI myocardial infarction, NS not significant, STS Society of Thoracic Surgeons

urgently and had more intraoperative IABP and ECMO usage compared with the survivors. They also had a greater proportion of shock as well as higher $\mathrm{Cr}$, and lower $\mathrm{Hb}$ levels after the operation. ICU stay was markedly prolonged in the mortality group.

\section{Scoring systems and in-hospital mortality}

The mean Society of Thoracic Surgeons (STS) mortality risk, European System for Cardiac Operative Risk Evaluation (EuroSCORE) II, SOFA, and APACHE II scores were $7.7,6.8,6.6$, and 12.9, respectively. All scores differed significantly between the survivors and nonsurvivors. The AUC results listed in Table 3 indicate that the SOFA, STS mortality risk, APACHE II, and EuroSCORE II all had satisfactory discriminatory ability $(0.912 \pm 0.019, P<.001$, $0.898 \pm 0.017, P<.001,0.866 \pm 0.027, P<.001$, and $0.863 \pm$ $0.022, P<.001)$. Both the SOFA and STS mortality risk 
Table 2 Postoperative outcomes and clinical characteristics of survival and mortality patients (Expressed as Mean \pm Standard Error)

\begin{tabular}{|c|c|c|c|c|}
\hline & $\begin{array}{l}\text { All Patients } \\
(n=483)\end{array}$ & $\begin{array}{l}\text { Survival } \\
(n=435)\end{array}$ & $\begin{array}{l}\text { Mortality } \\
(n=48)\end{array}$ & $p$-value \\
\hline \multicolumn{5}{|l|}{ Surgical detail } \\
\hline Urgent operation (\%) & $124(25.7)$ & $91(20.9)$ & $33(68.8)$ & $<0.001$ \\
\hline On pump (\%) & $332(68.7)$ & $293(67.4)$ & 39 (81.3) & 0.049 \\
\hline $\begin{array}{l}\text { On pump-clamp } \\
\text { time (minutes) }\end{array}$ & - & $89.7 \pm 3.4$ & $77.8 \pm 11.4$ & - \\
\hline $\begin{array}{l}\text { On pump-bypass } \\
\text { time (minutes) }\end{array}$ & - & $115.8 \pm 2.7$ & $135.5 \pm 11.1$ & - \\
\hline Bypass graft number & $2.98 \pm 0.04$ & $2.91 \pm 0.04$ & $2.69 \pm 0.09$ & 0.076 \\
\hline \multicolumn{5}{|l|}{ Postoperative data } \\
\hline IABP, (\%) & $111(23.0)$ & 95 (21.8) & $16(33.3)$ & 0.072 \\
\hline ECMO, (\%) & $26(5.4)$ & $11(2.5)$ & $15(31.3)$ & $<0.001$ \\
\hline Shock & $143(29.7)$ & $105(24.2)$ & $38(79.2)$ & $<0.001$ \\
\hline Bilirubin Total (units/L) & $1.18 \pm 0.04$ & $1.16 \pm 0.04$ & $1.29 \pm 0.14$ & 0.195 \\
\hline $\begin{array}{l}\text { Serum Creatinine } \\
(\mathrm{mg} / \mathrm{dL})\end{array}$ & $1.82 \pm 0.1$ & $1.68 \pm 0.10$ & $3.32 \pm 0.41$ & $<0.001$ \\
\hline Hemoglobin (g/dL) & $10.6 \pm 0.1$ & $10.7 \pm 0.1$ & $9.5 \pm 0.3$ & $<0.001$ \\
\hline \multicolumn{5}{|l|}{ Postoperative scores } \\
\hline SOFA & $6.6 \pm 0.1$ & $6.2 \pm 0.1$ & $10.8 \pm 0.4$ & $<0.001$ \\
\hline APACHE ॥ & $12.9 \pm 0.3$ & $12.0 \pm 0.2$ & $21.1 \pm 0.9$ & $<0.001$ \\
\hline \multicolumn{5}{|l|}{ Patient outcome } \\
\hline ICU stay (day) & $4.9 \pm 0.4$ & $4.4 \pm 0.4$ & $10.3 \pm 1.6$ & $<0.001$ \\
\hline
\end{tabular}

Abbreviations: ECMO Extracorporeal Membrane Oxygenation, IABP intra-aortic balloon pump, SOFA Sequential Organ Failure Assessment

were significantly superior to EuroSCORE II $(P=.016$ and $P<.001$, respectively). Low $P$ values for the Hosmer-Lemeshow test indicated that there were no statistical hints against an assumed fit of the scoring system. Both the postoperative SOFA and APACHE II scores exhibited close agreement between the observed and expected mortality. Figure 1 presents the observed and predicted mortality results for the scoring systems stratified into quintiles.

To investigate the individual organ systems that affect post-CABG mortality, we dissected the SOFA score components to calculate the discriminatory power of each (Table 4). The cardiovascular system followed by the renal system had the higher discriminatory power, after which were coagulation and neurology, both with similar discriminatory power. Liver and respiration had the lowest discriminatory power among the individual factors. Combining the cardiovascular and renal system components resulted in increased discriminatory power, but this power was still less than that of the entire SOFA score $(P<.001)$.

Figure 2 illustrates the cumulative survival rate, stratified according to SOFA score tertiles. Patients in the high and middle tertiles had significantly lower survival rates than did those in the low tertile $(\log$-rank $P<.001)$

\section{Logistic regression analysis for mortality according to postoperative variables}

According to univariable and multivariable logistic regression models based on patient characteristics and postoperative factors, only the age, postoperative ECMO and SOFA score were independently associated with mortality (Table 5).

\section{Discussion}

This present investigation examined 483 isolated CABG patients admitted to an ICU after operation. The overall inhospital mortality rate was $9.9 \%$, which was higher than that reported in previous studies. Tamayo et al. studied post-cardiac surgery patients and found a 90-day inhospital mortality rate of $8.8 \%$ [9]. Curiel-Balsera et al. performed a study using the ARIAM Andalus adult cardiac surgery registry, which included data from 11 hospitals in the autonomous region of Andalusia between 2008 and 2011, and reported intra-ICU mortality of $7.7 \%$ and 30-day mortality of 9.3\% [10]. Rodríguez-Rieiro et al. reported an observed mortality rate of $7.69 \%$ [11]. Our preoperative STS and EuroSCORE II scores were much higher than those reported in the literature [12-14]. Potential explanations for this are as follows. First, the current data were collected in the largest tertiary referral hospital in Northern Taiwan, in which a large proportion of patients have advanced comorbidities such as ESRD (11.8\%), which is well known to be a high-risk population for surgical mortality [15]. Second, in traditional Chinese culture, families typically seek treatment for patients even when doing so involves high surgical risk and a high likelihood of

Table 3 Calibration and discrimination results for the scoring methods in predicting mortality

\begin{tabular}{|c|c|c|c|c|c|c|}
\hline & \multicolumn{3}{|l|}{ Calibration } & \multicolumn{3}{|l|}{ Discrimination } \\
\hline & goodness-of-fit $\left(x^{2}\right)$ & $d f$ & $p$ & $\mathrm{AUC} \pm \mathrm{SE}$ & $95 \% \mathrm{Cl}$ & $p$ \\
\hline Postoperative SOFA & 3.361 & 6 & 0.762 & $0.912 \pm 0.019$ & $0.875-0.949$ & $<0.001$ \\
\hline Postoperative APACHE II & 6.335 & 8 & 0.610 & $0.866 \pm 0.027$ & $0.813-0.919$ & $<0.001$ \\
\hline STS-risk of mortality & 29.654 & 8 & $<0.001$ & $0.898 \pm 0.017$ & $0.864-0.932$ & $<0.001$ \\
\hline EuroSCORE ॥ & 40.472 & 8 & $<0.001$ & $0.863 \pm 0.022$ & $0.821-0.906$ & $<0.001$ \\
\hline
\end{tabular}

Abbreviations: APACHE Acute Physiology and Chronic Health Evaluation, AUC area under the curve, Cl confidence interval, df degree of freedom, EuroSCORE European System for Cardiac Operative Risk Evaluation, SE standard error, SOFA Sequential Organ Failure Assessment, STS Society of Thoracic Surgeons 

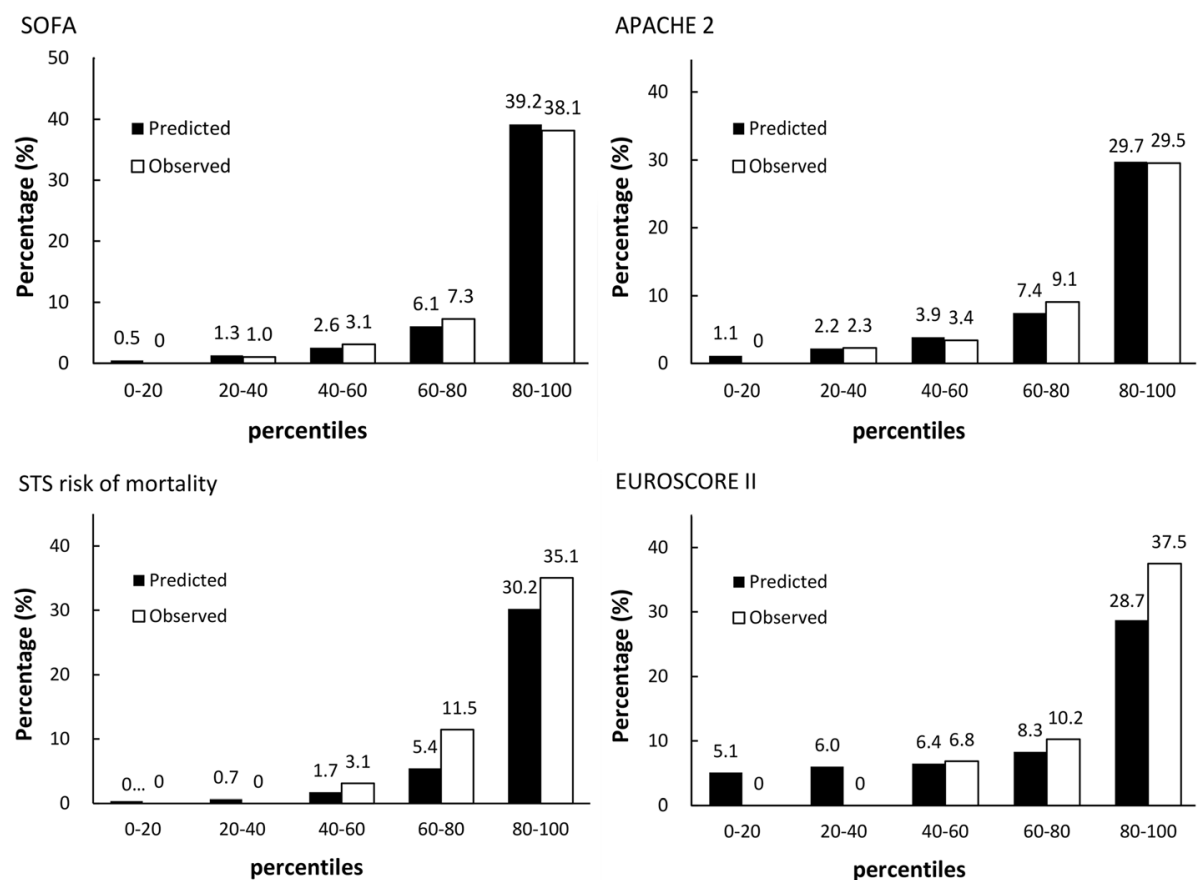

EUROSCORE II

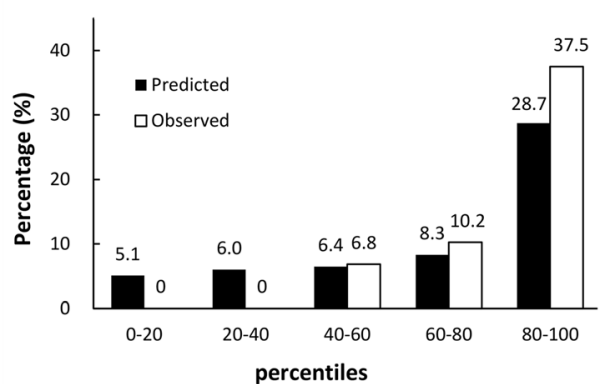

Fig. 1 Observed and expected (mean) mortality rates divided by quintiles of expected mortality calculated using the STS risk model, EuroSCORE II, SOFA, and APACHE II

complications [16]. Third, of the patients who underwent emergent and salvage CABG, some had severe preoperative cardiogenic shock (12.4\%) and received mechanical circulatory support (MCS), namely patients with IABP $(13.2 \%)$ and ECMO (2.5\%), both of which are positively associated with CABG mortality. Early mortality in patients undergoing emergent and salvage CABG is substantial, with the in-hospital mortality rates of 13 and 41\%, respectively [17]. Patients requiring preoperative MCS have operative mortality of $37.2 \%$, and those undergoing CABG as a salvage procedure have an operative mortality of 53.3\% [18]. Finally, the low total hospital costs (approximately 10\% of the costs in the United States) and large reimbursement amounts under the health insurance system of Taiwan may have affected the quality of patient care and negatively affected the CABG outcomes [19].
Numerous prognostic risk models for cardiac surgery have been introduced into current practice. Among them, the EuroSCORE, published in 1999 [20]; revised EuroSCORE II, published in 2012 [21]; and STS score, published in 2008 [22] are widely used. These assessments, which are based on collected data, can be used to predict the risk of cardiac surgery mortality according to patient demographics and clinical variables, and can be determined using an easy-touse online calculator. No previous study has compared preoperative and postoperative risk modes for predicting the occurrence of mortality in isolated CABG. Our data showed that preoperative scores underestimated mortality in highrisk patients (Fig. 1). Thus, a postoperative score is necessary for ICU doctors to reevaluate condition severity. In this study, we demonstrated that SOFA and APACHE II scores at ICU day 1 have similar predictive effectiveness for

Table 4 Calibration and discrimination results for each sofa parameter in predicting mortality

\begin{tabular}{|c|c|c|c|c|c|c|}
\hline & \multicolumn{3}{|l|}{ Calibration } & \multicolumn{3}{|l|}{ Discrimination } \\
\hline & goodness-of-fit $\left(x^{2}\right)$ & $d f$ & $p$ & $\mathrm{AUC} \pm \mathrm{SE}$ & $95 \% \mathrm{Cl}$ & $p$ \\
\hline Respiration & 6.006 & 1 & 0.014 & $0.529 \pm 0.046$ & $0.439-0.619$ & 0.524 \\
\hline Renal & 16.566 & 2 & $<0.001$ & $0.803 \pm 0.033$ & $0.738-0.867$ & $<0.001$ \\
\hline Liver & 0.421 & 1 & 0.516 & $0.578 \pm 0.048$ & $0.484-0.673$ & 0.087 \\
\hline Cardiovascular & 2.947 & 3 & 0.400 & $0.805 \pm 0.034$ & $0.737-0.872$ & $<0.001$ \\
\hline Coagulation & 2.929 & 1 & 0.087 & $0.677 \pm 0.047$ & $0.584-0.770$ & $<0.001$ \\
\hline Neurological & 5.550 & 1 & 0.018 & $0.703 \pm 0.048$ & $0.608-0.797$ & $<0.001$ \\
\hline Cardiovascular + Renal & 2.303 & 4 & 0.680 & $0.871 \pm 0.023$ & $0.825-0.917$ & $<0.001$ \\
\hline
\end{tabular}




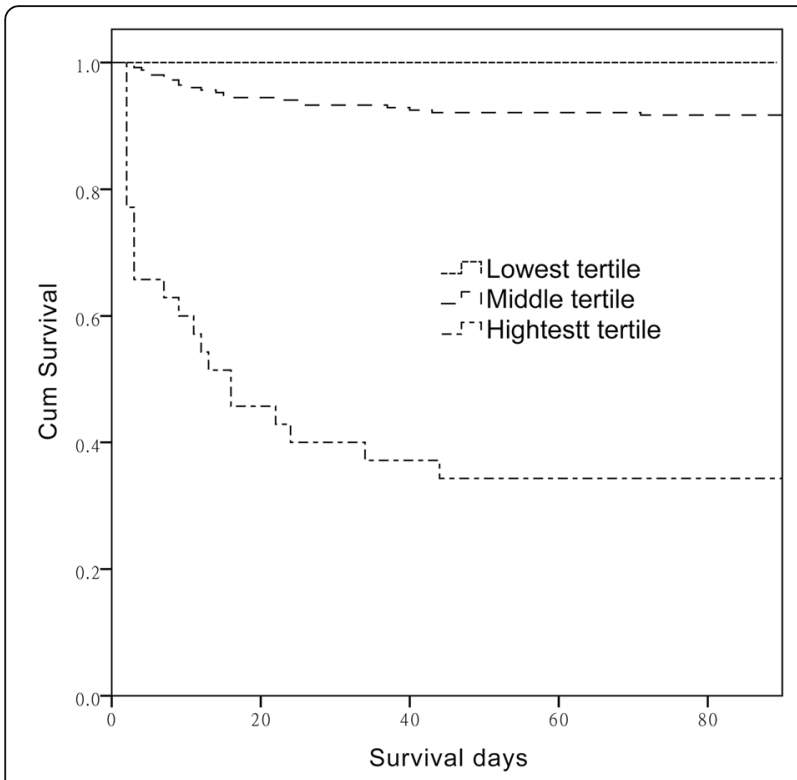

Fig. 2 Kaplan-Meier survival curves of mortality with log-rank test results according to SOFA score tertiles

mortality. SOFA score based upon respiratory, renal, hepatic, cardiovascular, neurological and coagulation systems, were used as an assessment tool to evaluate outcome. The Cardiac Surgery Score (CASUS) was designed for predicting cardiac surgery mortality by using 10 variables measured upon ICU admission [23]. Several studies have concluded

Table 5 Logistic regression analysis of postoperative factors for mortality

\begin{tabular}{lllll}
\hline Parameter & $\begin{array}{l}\text { Beta } \\
\text { Coefficient }\end{array}$ & $\begin{array}{l}\text { Standard } \\
\text { error }\end{array}$ & $\begin{array}{l}\text { Odds ratio } \\
(95 \% \mathrm{Cl})\end{array}$ & $p$ \\
\hline Univariate logistic regression & & & \\
Age & 0.052 & 0.016 & $1.053(1.022-1.086)$ & 0.001 \\
$\begin{array}{l}\text { Diabetes } \\
\text { mellitus }\end{array}$ & 0.300 & 0.312 & $1.350(0.732-2.489)$ & 0.336 \\
Hypertension & 0.294 & 0.357 & $0.342(0.667-2.699)$ & 0.409 \\
ESRD & 1.207 & 0.356 & $3.342(1.662-6.719)$ & 0.001 \\
Serum & 0.211 & 0.054 & $1.235(1.111-1.372)$ & $<0.001$ \\
Creatinine & & & & \\
Hemoglobin & -0.412 & 0.100 & $0.662(0.545-0.805)$ & $<0.001$ \\
IABP & 0.576 & 0.330 & $1.779(0.923-3.394)$ & 0.081 \\
ECMO & 2.962 & 0.459 & $13.343(7.876-47.560)$ & $<0.001$ \\
SOFA & 0.737 & 0.151 & $2.090(1.556-2.807)$ & $<0.001$ \\
Multivariate logistic regression & & & \\
Age & 0.062 & 0.021 & $1.064(1.020-1.110)$ & 0.004 \\
ECMO & 2.298 & 0.678 & $9.959(2.636-37.620)$ & 0.001 \\
SOFA & 0.711 & 0.097 & $2.036(1.685-2.460)$ & $<0.001$ \\
Constant & -12.623 & 1.851 & - & - \\
\hline Abbreviations: ECMO Extracorporeal Membrane Oxygenation, IABP intra &
\end{tabular}

Abbreviations: ECMO Extracorporeal Membrane Oxygenation, IABP intra-aortic balloon pump, SOFA Sequential Organ Failure Assessment that the scale can effectively predict cardiac surgery mortality, and have recommended its use [24]. The CASUS also evaluates several organ functions and has similar parameters to those of SOFA. However, lactic acid was not routinely recorded postoperatively in our ICU; thus, we could not validate CASUS results in this study. The Post Cardiac Surgery (POCAS) prognostic score was developed on the basis of 4 parameters (mean arterial pressure [MAP], lactate, bicarbonate, and international normalized ratio [INR]), and has favorable discrimination in predicting postcardiac mortality [9]. Although we did not compare POCAS and SOFA scores, MAP and lactate represent the cardiac system, bicarbonate represents the renal system, and the INR represents coagulation and the liver system, which might explain why the SOFA and POCAS results were similar.

Patients receiving CABG mainly exhibit 2 complex cardiorenal syndromes. First, patients with coronary arterial disease are usually older and have DM, HTN, and CHF, which cause chronic kidney disease (CKD) through microvascular and macrovascular pathophysiology. Moreover, sympathetic tone, renin-angiotensin-aldosterone system activation, and endothelin release cause excess vasoconstriction and impair glomerular filtration. CKD also induces erythropoietin deficiency, decreased vitamin $\mathrm{D}$ receptor activation, and fluid acumination, which might affect cardiac function through cardiomyopathy. Second, during CABG, patients experience low cardiac output, nonpulsatile blood flow, hemolysis, and free iron release, which induce oxidative stress and reactive oxygen species and impair kidney function. Otherwise, excess diuretic and analgesic use might result in acute kidney injury (AKI). In fact, AKI affects 12$30 \%$ of patients undergoing CABG, contributes to increased in-hospital mortality and reduced long-term survival, and results in high medical expenditure, CKD, and dialysis dependence [25-28]. Postoperative AKI not only contributes to increased in-hospital mortality and reduced long-term survival but also results in high medical expenditure, CKD, and dialysis dependence. In the present study, the mortality group patients exhibited anemia, hypoalbuminemia, and poor renal function, which reflect the severity of heart failure, water retention, inflammation, and malnutrition and which are known risk factors for mortality after cardiac surgery $[14,29,30]$. The occurrence of cardiac and renal dysfunction varies among patients admitted to the ICU with CABG, with different degrees of association existing between individual organ system failure and ICU mortality [31]. This explains why combining the cardiac and renal factors of the SOFA score is an accurate technique for assessing mortality in patients who receive CABG.

\section{Study limitations}

Despite the favorable results obtained in this study, some crucial limitations must be noted. First, our study was limited by its post hoc analysis nature and relatively 
small number of cases from a single referral center in Asia; care should be used when generalizing the results to different populations. Second, scoring was performed only on the first day of ICU admission. The sequential application of these scoring systems (for example, daily or weekly) may reflect dynamic aspects of clinical diseases and thus provide more complete data on mortality risk. Finally, the etiology of mortality is often multifactorial, and postoperative care factors that were not included in the scoring systems may have affected the prediction results.

\section{Conclusions}

The analysis results highlight the strong discriminative power of the SOFA and APACHE II scores in predicting mortality in patients after CABG. Among the different components of the SOFA, renal dysfunction is the only one that is also incriminated in cardiac failure, indicating that mortality is often part of a cardiorenal syndrome. The multivariate analysis identified the SOFA score alone as an independent risk factor for mortality. Higher SOFA scores are correlated with higher mortality. In conclusion, SOFA might be the most effective tool for guiding the use of preventive and early therapeutic strategies to prevent mortality and improve clinical outcomes for patients who undergo CABG. Future studies could conduct multicenter and repeated measurements to enhance accuracy for future clinical management.

\section{Acknowledgements}

The authors also thank all entire surgical team and staff of the Kidney Research Center of Chang Gung Memorial Hospital, Linkou, Taiwan.

\section{Funding}

This study was supported by grants from Chang Gung Memorial Hospital, Taiwan (BMRPD97). Dr. C-H Chang was supported by the Ministry of Science and Technology (MOST 103-2314-B-182A-018-MY3).

\section{Availability of data and materials}

The data that support the findings of this study are available from the department of cardiovascular surgery of the Chang Gung Memorial Hospital but restrictions apply to the availability of these data, which were used under license for the current study, and so are not publicly available. Data are however available from the authors upon reasonable request and with permission of Liver Transplantation Center of the Chang Gung Memorial Hospital.

\section{Authors' contributions}

Contributorship statement: C-H Chang and S-W Chen participated in all works aspects of present study. F-C Tsai is a surgeon and consultant. C-H Chang and $\mathrm{Y}-\mathrm{C} C$ Chen devised with the hypothesis, and were responsible for the design. S-W Chang is a biostatistician who analyzed the data with P-C Fan, C-C Lee, H-C Pan and $\mathrm{C}-\mathrm{H}$ Chang. $\mathrm{H}-\mathrm{Y}$ Yang and C-W Yang assisted manuscript preparation and editing. All authors read and approved the final manuscript.

\section{Competing interests}

The authors declare no competing financial interests.

\section{Consent for publication}

Not applicable.

\section{Ethics approval and consent to participate}

This clinical investigation was approved by the Institutional Review Board of Chang Gung Memorial Hospital (approval No. 103-6381B). The protocol of the study was designed in full compliance with Good Clinical Practice guidelines and the principles of the Declaration of Helsinki. In this study, no organs from executed persons were used. Because only pre-existing data were examined, we did not obtain written informed consent from each patient. Instead, patients were informed of their right for accepting or refusing enrollment by telephone interview. Before data analysis, the records of patients were anonymized and de-identified. The approaches followed the ordinances concerning informed consent and enrollment expounded in guidelines.

\section{Author details}

${ }^{1}$ Kidney Research Center, Department of Nephrology, Chang Gung Memorial Hospital, Linkou Medical Center, Taoyuan, Taiwan. ${ }^{2}$ Department of Cardiothoracic and Vascular Surgery, Chang Gung Memorial Hospital, Linkou Medical Center, Taoyuan, Taiwan. ${ }^{3}$ Department of Nephrology, Chang Gung Memorial Hospital, Keelung branch, New Taipei City, Taiwan. ${ }^{4} \mathrm{Clinical}$ Informatics and Medical Statistics Research Center, College of Medicine, Chang Gung University, Taoyuan, Taiwan. ${ }^{5}$ School of medicine, College of Medicine, Chang Gung University, 199 Tung Hwa North Road, Taoyuan, Taipei 105, Taiwan.

Received: 7 October 2016 Accepted: 25 February 2017 Published online: 06 March 2017

\section{References}

1. Mehta RH, Suzuki T, Hagan PG, Bossone E, Gilon D, Llovet A, Maroto LC, Cooper JV, Smith DE, Armstrong WF, et al. Predicting death in patients with acute type a aortic dissection. Circulation. 2002;105(2):200-6.

2. Siregar S, Groenwold RH, de Mol BA, Speekenbrink RG, Versteegh MI, Brandon Bravo Bruinsma GJ, Bots ML, van der Graaf Y, van Herwerden LA. Evaluation of cardiac surgery mortality rates: 30-day mortality or longer follow-up? Eur J Cardiothorac Surg. 2013;44(5):875-83.

3. Chang $\mathrm{CH}$, Lee CC, Chen SW, Fan PC, Chen YC, Chang SW, Chen TH, Wu VC, Lin PJ, Tsai FC. Predicting acute kidney injury following mitral valve repair. Int J Med Sci. 2016;13(1):19-24.

4. Knaus WA, Zimmerman JE, Wagner DP, Draper EA, Lawrence DE. APACHEacute physiology and chronic health evaluation: a physiologically based classification system. Crit Care Med. 1981;9(8):591-7.

5. Vincent JL, Moreno R, Takala J, Willatts S, De Mendonca A, Bruining H, Reinhart CK, Suter PM, Thijs LG. The SOFA (sepsis-related organ failure assessment) score to describe organ dysfunction/failure. On behalf of the working group on sepsis-related problems of the European society of intensive care medicine. Intensive Care Med. 1996;22(7):707-10.

6. Chang CH, Fan PC, Chang MY, Tian YC, Hung CC, Fang JT, Yang CW, Chen YC. Acute kidney injury enhances outcome prediction ability of sequential organ failure assessment score in critically ill patients. PLoS One. 2014;9(10): e109649.

7. Hillis LD, Smith PK, Anderson JL, Bittl JA, Bridges CR, Byrne JG, Cigarroa JE, Disesa VJ, Hiratzka LF, Hutter Jr AM, et al. 2011 ACCF/AHA guideline for coronary artery bypass graft surgery: a report of the American college of cardiology foundation/American heart association task force on practice guidelines. Circulation. 2011;124(23):e652-735.

8. DeLong ER, DeLong DM, Clarke-Pearson DL. Comparing the areas under two or more correlated receiver operating characteristic curves: a nonparametric approach. Biometrics. 1988;44(3):837-45.

9. Tamayo E, Fierro I, Bustamante-Munguira J, Heredia-Rodriguez M, JorgeMonjas P, Maroto L, Gomez-Sanchez E, Bermejo-Martin F, Alvarez F, GomezHerreras J. Development of the post cardiac surgery (POCAS) prognostic score. Crit Care. 2013;17(5):R209.

10. Curiel-Balsera E, Mora-Ordonez JM, Castillo-Lorente E, Benitez-Parejo J, Herruzo-Aviles A, Ravina-Sanz JJ, Alvarez-Bueno M, Rivera-Fernandez R. Mortality and complications in elderly patients undergoing cardiac surgery. J Crit Care. 2013;28(4):397-404.

11. Rodriguez-Rieiro C, Rodriguez Perez P, Granado de la Orden S, Moreno M, Garcia AC, Sanchez-Gomez A. In-hospital mortality rates after CABG by autonomous regions in Spain. Int J Health Care Qual Assur. 2011;24(4):300-7.

12. Kennedy JL, LaPar DJ, Kern JA, Kron IL, Bergin JD, Kamath S, Ailawadi G. Does the society of thoracic surgeons risk score accurately predict operative 
mortality for patients with pulmonary hypertension? J Thorac Cardiovasc Surg. 2013;146(3):631-7.

13. Edgerton J, Filardo G, Ryan WH, Brinkman WT, Smith RL, Hebeler Jr RF, Hamman B, Sass DM, Harbor JP, Mack MJ. Risk of not being discharged home after isolated coronary artery bypass graft operations. Ann Thorac Surg. 2013;96(4):1287-92.

14. Poullis M, Pullan M, Chalmers J, Mediratta N. The validity of the original EuroSCORE and EuroSCORE II in patients over the age of seventy. Interact Cardiovasc Thorac Surg. 2015;20(2):172-7.

15. Rahmanian PB, Adams DH, Castillo JG, Vassalotti J, Filsoufi F. Early and late outcome of cardiac surgery in dialysis-dependent patients: single-center experience with 245 consecutive patients. J Thorac Cardiovasc Surg. 2008; 135(4):915-22.

16. Wen KY, Lin YC, Cheng JF, Chou PC, Wei CH, Chen YF, Sun JL. Insights into Chinese perspectives on do-not-resuscitate (DNR) orders from an examination of DNR order form completeness for cancer patients. Support Care Cancer. 2013;21(9):2593-8.

17. Axelsson TA, Mennander A, Malmberg M, Gunn J, Jeppsson A, Gudbjartsson T. Is emergency and salvage coronary artery bypass grafting justified? The Nordic Emergency/Salvage coronary artery bypass grafting study. Eur J Cardiovasc Thorac Surg. 2016;49(5):1451-6. doi:10.1093/ejcts/ezv388.

18. Acharya D, Gulack BC, Loyaga-Rendon RY, Davies JE, He X, Brennan JM, Thourani VH, Williams ML. Clinical characteristics and outcomes of patients with myocardial infarction and cardiogenic shock undergoing coronary artery bypass surgery: data from the society of thoracic surgeons national database. Ann Thorac Surg. 2016;101(2):558-66.

19. Chang GM, Cheng SH, Tung YC. Impact of cuts in reimbursement on outcome of acute myocardial infarction and use of percutaneous coronary intervention: a nationwide population-based study over the period 1997 to 2008. Med Care. 2011;49(12):1054-61.

20. Nashef SA, Roques F, Michel P, Gauducheau E, Lemeshow S, Salamon R. European system for cardiac operative risk evaluation (EuroSCORE). Eur J Cardiothorac Surg. 1999;16(1):9-13.

21. Nashef SA, Roques F, Sharples LD, Nilsson J, Smith C, Goldstone AR, Lockowandt U. EuroSCORE II. Eur J Cardiothorac Surg. 2012;41(4):734-44. discussion 744-735.

22. O'Brien SM, Shahian DM, Filardo G, Ferraris VA, Haan CK, Rich JB, Normand SL, DeLong ER, Shewan CM, Dokholyan RS, et al. The society of thoracic surgeons 2008 cardiac surgery risk models: part 2-isolated valve surgery. Ann Thorac Surg. 2009;88(1 Suppl):S23-42.

23. Hekmat K, Kroener A, Stuetzer H, Schwinger RH, Kampe S, Bennink GB, Mehlhorn U. Daily assessment of organ dysfunction and survival in intensive care unit cardiac surgical patients. Ann Thorac Surg. 2005;79(5):1555-62.

24. Badreldin A, Elsobky S, Lehmann T, Brehm BB, Doenst T, Hekmat K. Daily-MeanSOFA, a new derivative to increase accuracy of mortality prediction in cardiac surgical intensive care units. Thorac Cardiovasc Surg. 2012;60(1):43-50

25. Gallagher S, Jones DA, Lovell MJ, Hassan S, Wragg A, Kapur A, Uppal R, Yaqoob MM. The impact of acute kidney injury on midterm outcomes after coronary artery bypass graft surgery: a matched propensity score analysis. J Thorac Cardiovasc Surg. 2014;147(3):989-95.

26. Ryden L, Ahnve S, Bell M, Hammar N, Ivert T, Sartipy U, Holzmann MJ. Acute kidney injury after coronary artery bypass grafting and long-term risk of myocardial infarction and death. Int J Cardiol. 2014;172(1):190-5.

27. Rosner MH, Okusa MD. Acute kidney injury associated with cardiac surgery. Clin J Am Soc Nephrol. 2006;1 (1):19-32.

28. Chen YC, Tsai FC, Chang CH, Lin CY, Jenq CC, Juan KC, Hsu HH, Chang MY, Tian YC, Hung CC, et al. Prognosis of patients on extracorporeal membrane oxygenation: the impact of acute kidney injury on mortality. Ann Thorac Surg. 2011;91(1):137-42.

29. Tang YD, Katz SD. Anemia in chronic heart failure: prevalence, etiology, clinical correlates, and treatment options. Circulation. 2006;113(20):2454-61.

30. Silverberg DS. The role of erythropoiesis stimulating agents and intravenous (IV) iron in the cardio renal anemia syndrome. Heart Fail Rev. 2011;16(6):609-14

31. Lin YF, Ko WJ, Wu VC, Chen YS, Chen YM, Hu FC, Shiao CC, Wu MS, Chen YW, Li WY, et al. A modified sequential organ failure assessment score to predict hospital mortality of postoperative acute renal failure patients requiring renal replacement therapy. Blood Purif. 2008;26(6):547-54.

\section{Submit your next manuscript to BioMed Central and we will help you at every step:}

- We accept pre-submission inquiries

- Our selector tool helps you to find the most relevant journal

- We provide round the clock customer support

- Convenient online submission

- Thorough peer review

- Inclusion in PubMed and all major indexing services

- Maximum visibility for your research

Submit your manuscript at www.biomedcentral.com/submit

) Biomed Central 